\title{
Heterogeneous Associations Between Obesity and Reproductive-Related Factors and Specific Breast Cancer Subtypes Among Hong Kong Chinese Women
}

\author{
Priscilla Ming Yi Lee ${ }^{1}$ Chi hei Kwok ${ }^{2} \cdot$ Wing Cheong Chan ${ }^{3} \cdot{\text { Cherry } \mathrm{Wu}^{4} \cdot \mathrm{Koon}^{-} \text {ho Tsang }}^{5} \cdot$ Sze-hong Law $^{6}$. \\ Yiu-cheong Yeung ${ }^{7} \cdot$ Feng Wang $^{1} \cdot$ Xiaohong R. Yang $^{8} \cdot$ Lap Ah Tse $^{1}$
}

Received: 19 March 2020 / Accepted: 21 May 2020 / Published online: 3 June 2020

(C) Springer Science+Business Media, LLC, part of Springer Nature 2020

\begin{abstract}
Previous studies reported heterogeneous associations between obesity and reproductive-related breast cancer risk factors and breast cancer intrinsic subtypes; however, few studies have been conducted in Asian populations. Here, we aimed to examine whether risks associated with established breast cancer risk factors varied by breast cancer subtypes in Chinese women. We conducted a hospital-based case-control study in Hong Kong, including a total of 2169 Chinese women. Unconditional polytomous logistic regression models were used to calculate adjusted odds ratios (AORs) and 95\% confidence intervals $(95 \% \mathrm{CIs})$ to estimate relative risks associated with examined risk factors in case-control analyses and to test for heterogeneity across breast cancer subtypes in case-case analyses. In case-case analyses, compared with luminal A patients, luminal $\mathrm{B}(\mathrm{AOR}=1.76,95 \% \mathrm{CI}=1.07-2.88)$, HER2 overexpressing ( $\mathrm{AOR}=3.40,95 \% \mathrm{CI}=1.56-7.39)$, and triple negative (TNBC, $\mathrm{AOR}=2.39,95 \% \mathrm{CI}=1.18-4.82$ ) patients were more likely to be postmenopausal. In case-control analyses, reduced risks associated with parity and younger age at first birth were only seen for luminal A and B cases especially among postmenopausal women, whereas having $\geq 3$ children was associated with increased risk for HER2 overexpressing and TNBC among premenopausal women. Obesity was associated with increased risk for all subtypes. We found heterogeneous associations between parity-related risk factors by menopausal status and breast cancer subtypes among Chinese patients, which is similar to those observed in Western populations. Interestingly, obesity was associated with increased breast cancer risk regardless of menopausal status or subtypes, except for premenopausal luminal patients, which appears to be unique in Asian populations.
\end{abstract}

Keywords Breast cancer $\cdot$ Reproductive-related factors $\cdot$ Body mass index $\cdot$ Breast cancer subtypes $\cdot$ Asian

$\overline{\text { Priscilla Ming Yi Lee and Chi hei Kwok are equal contribution as co-first }}$ author.

Xiaohong R. Yang and Lap Ah Tse are co-senior authors.

Electronic supplementary material The online version of this article (https://doi.org/10.1007/s12672-020-00386-2) contains supplementary material, which is available to authorized users.

Xiaohong R. Yang

royang@mail.nih.gov

$\checkmark$ Lap Ah Tse

shelly@cuhk.edu.hk

1 JC School of Public Health and Primary Care, The Chinese University of Hong Kong, Shatin, NT, Hong Kong, SAR, China

2 Department of Oncology, Princess Margaret Hospital, Kwai Chung, Hong Kong, SAR, China

3 Department of Surgery, North District Hospital, Sheung Shui, Hong Kong, SAR, China
4 Department of Pathology, North District Hospital, Sheung Shui, Hong Kong, SAR, China

5 Department of Pathology, Yan Chai Hospital, Tsuen Wan, Hong Kong, SAR, China

6 Department of Surgery, Yan Chai Hospital, Tsuen Wan, Hong Kong, SAR, China

7 Department of Medicine, Princess Margaret Hospital, Kwai Chung, Hong Kong, SAR, China

8 Division of Cancer Epidemiology \& Genetics, National Cancer Institute, National Institutes of Health, Bethesda, MD, USA 


\section{Background}

Breast cancer is a heterogeneous disease [1]. According to the 2013 St Gallen Internation Expect Consensus, the expert panel defined and adopted four major breast cancer intrinsic subtypes determined by the expression of estrogen receptor (ER), progesterone receptor (PR), human epidermal growth factor receptor-2 (HER2), and Ki-67 [2]. These four breast cancer subtypes (hormone receptor-positive tumors: luminal A and luminal B; and hormone receptor negative tumors: HER2 overexpressing and triple negative) demonstrate different distributions of age of onset, prognosis, and ethnicity [3-5].

Epidemiologic studies have shown that established breast cancer risk factors may have differential effects on breast cancer subtypes, suggesting that these subtypes may derive from distinct etiologic pathways $[6,7]$. For example, reproductiverelated factors such as more parities and earlier age at first birth were associated with reduced risks of luminal breast cancer subtypes, but they may even increase the risk of triple negative breast cancer [8]. However, most of the existing evidences regarding etiologic heterogeneity by breast cancer subtypes are based on Western studies [9, 10]. A recent case-only analysis conducted in Malaysia showed different distributions of parity, breastfeeding, and obesity across different subtypes [11]. Another case-control study from China found that overweight and breastfeeding were associated with increased risk of all subtypes of breast cancer [12]; however, this type of analyses, especially involving appropriate controls and case subtypes, in Asian populations are limited.

During the past two decades, incidence rates of breast cancer have increasing rapidly in most Asian countries [13], which may be attributed to the adoption of a Westernized lifestyle such as increasing obesity and changing reproductive patterns [14]. The recent generations of Hong Kong women are experiencing epidemiological transitions on reproductiverelated risk factors, and these may have influenced the distribution of sex-hormone receptor-specific breast cancer. Age at menarche among Chinese women has shifted to an earlier age [15], while the median age at first birth has delayed substantially from 25.1 years in 1981 to 31.6 years in 2017 [16]. The prevalence of obesity is still lower in Hong Kong compared with most Western countries, but it has been increasing over the years [17]. In contrast to the protective effect of obesity among premenopausal women seen in Western populations, studies have shown that obesity is associated with increased breast cancer risk regardless of menopausal status in Asian women [18]. The heterogeneity of breast cancer risk associated with obesity by tumor subtypes among Asian breast cancer cases remains unclear.

In this study, we evaluated the associations between established breast cancer risk factors and breast cancer subtypes in a breast cancer case-control study conducted in Hong Kong.

\section{Methods}

\section{Study Population and Design}

We conducted a hospital-based case-control study in three public hospitals in Hong Kong between November 2011 and January 2018. We defined cases as Chinese women aged 2084 years old who were newly diagnosed with primary breast cancer (International Classification of Disease, Tenth Revision, code C50) within 3 months prior to the interview. Cases with prior-surgery treatment on breasts were excluded. Each control was matched to a case using frequency matching in a 5-year age group, and controls were recruited from the same hospital where the cases were identified. Controls had a broad spectrum of diagnoses that were unrelated to breast cancer conditions (i.e., diseases of the digestive system, diseases of the circulatory system, diseases of the genitourinary system, endocrine, nutritional and metabolic diseases, and diseases of the nervous system). We excluded cases and controls if they had prior history of physician-diagnosed cancer in any site. A total number of 1156 cases and 1013 controls were recruited in this study with a response rate of 88.4 and $89.5 \%$, respectively. This study was approved by the Joint Chinese University of Hong Kong-New Territories East Cluster Clinical Research Ethics Committee and the Ethics Committee of Kowloon West Cluster, and all participants signed written informed consent forms before the fieldwork prior to the interviews.

Trained interviewers performed a face-to-face interview using standardized questionnaires to obtain information on socio-demographic characteristics, tobacco smoking, alcohol drinking and dietary habits, reproductive-related factors, anthropometric risk factors, history of chronic diseases, history of breast examination and surgery, physical activity, and occupational history including shift work. Risk factors focused in this analysis included body mass index (BMI) and reproductive-related factors including age at menarche, menopausal status, age at first birth, number of children (parity), and overall duration of breastfeeding. In addition, each participant was asked to report whether any of her first degree relatives had a history of cancer diagnosed by physicians.

We extracted clinical data on tumor characteristics for breast cancer cases (such as ER, PR, HER2, Ki67, and histological grade) from hospital medical records and pathology reports. Cases with ER or PR Allred score of $3 / 8$ or above or $\mathrm{H}$ score of $51 / 300$ or above were defined as positive status [19]. Cases with HER2 results of 0 and $1+$ on immunohistochemistry (IHC) testing were defined as HER2-negative (HER2-) and results of 3+ were identified as HER2-positive (HER2+). IHC result of $2+$ was defined as HER2- if subsequent fluorescence in situ hybridization (FISH) or chromogenic in situ hybridization (CISH) was negative. Given the majority $(80 \%)$ of patients with known FISH/CISH results 
of HER2 2+ were HER-, we defined IHC result of 2+ with missing FISH or CISH data as HER2-.

We classified cases into four intrinsic subtypes according to the suggestion by the 2013 St Gallen International Expert Consensus [2], including luminal A [ER+ and PR+ and HER2 - and $(\mathrm{Ki}-67<20 \%$ or histological grade $\mathrm{I} / \mathrm{II})$ ], luminal $\mathrm{B}$ ["ER+ and HER2- and (PR- or Ki-67 $\geq 20 \%$ or histological grade III)" or "ER+ and HER2+"], HER 2 overexpressing (ER - and PR- and HER2+), and triple negative (ER- and PRand HER2-).

\section{Statistical Analysis}

We used one-way ANOVA and chi-square test to compare differences in categorical and continuous variables among breast cancer subtypes. For case-only analysis, polytomous logistic regression model was used to estimate the adjusted odds ratios (AORs) and 95\% confidence intervals (95\% CIs) for associations between BMI, reproductive-related factors, and breast cancer subtypes. As the outcome endpoints for case-only analysis are not binary variable, we used a single multinomial model rather than a sequence of binary choices in the data analysis using the luminal $\mathrm{A}$ as the reference to look into whether different breast cancer subtypes shared similar risk factors of reproductive-related factors, with the mutual adjustment of factors including age, family history of breast cancer, age at menarche, age at first birth/parity, menopausal status, breastfeeding frequency, and BMI. We combined overweight (BMI 25.0-29.9) and obesity (BMI $\geq 30$ ) categories due to the low frequency of obesity in this study population. For case-control analysis, we used unconditional multivariate logistic regression model to estimate the risk for each subtype compared to controls for BMI and reproductive-related factors with the adjustment of the same set of risk factors as mentioned above. We further conducted a stratified analysis according to menopausal status for parity and BMI since these factors have previously shown effect modification by menopausal status. Due to small sample size in the stratified analysis, and also considering the correlation of hormone status with menopausal status, parity, and BMI [20], we combined luminal A and luminal B into a luminal group (i.e., hormone receptor-positive tumors), and combined HER2 overexpressing and triple negative into a non-luminal group (i.e., hormone receptor-negative tumors). Sensitivity analysis was conducted by removing control patients with ovarian and related diseases (International Classification of Disease, Tenth Revision, code N00-N99), and endocrine, nutritional, and metabolic diseases (International Classification of Disease, Tenth Revision, code E00-E99) and diseases of the circadian system (International Classification of Disease, Tenth Revision, code I00-I99) from our analysis to evaluate the effect of ovarian diseases on reproductive-related factors, and effect of metabolic diseases and circadian systems disorders on BMI. All statistical analyses were performed using SPSS 24.0 for Windows (SPSS, Chicago, IL, USA), and a two-sided $p$ value less than 0.05 was considered statistically significant.

\section{Results}

A total of 923 (80\% from 1156) breast cancer cases with known status of ER, PR, HER2, and Ki67 or histological grade status were included in this report. The most prevalent subtype was luminal B $(393,43 \%)$, followed by luminal A (294, 31\%), triple negative (137, 15\%), and HER2 overexpressing $(99,11 \%)$. The distribution of selected risk factors of breast cancer among breast cancer subtypes are summarized in Table 1. HER2 overexpressing and triple negative breast cancer cases were more likely to be younger than luminal A and luminal B patients. Family history of breast cancer and other examined factors did not vary significantly by subtypes. Those with missing BMI value were relatively older, later age at menarche, and more likely to have missing value in other reproductive variables (Supplementary Table 1).

Table 2 shows the associations between examined risk factors and breast cancer subtypes in case-case comparisons. Compared with luminal A patients, luminal $\mathrm{B}(\mathrm{AOR}=1.76$, 95\% CI $=1.07-2.88)$, HER2 overexpressing $(\mathrm{AOR}=3.40$, $95 \% \mathrm{CI}=1.22-7.39)$, and triple negative ( $\mathrm{AOR}=2.39,95 \%$ $\mathrm{CI}=1.18-4.82$ ) patients were more likely to be postmenopausal. Triple negative patients were more likely were younger at first child birth $(\mathrm{AOR}=2.61,95 \% \mathrm{CI}=1.18-4.82$, aged $<26$ years old compared to nulliparity) than luminal A patients. In general, breastfeeding was less common among HER2 overexpressing and triple negative breast cancer women compared with luminal A women, but the differences did not reach the statistical significance (Table 2).

Table 3 summarizes the results from case-control comparisons showing overall and subtype-specific breast cancer risks associated with selected breast cancer risk factors. Compared to controls, luminal A cases $(\mathrm{AOR}=0.37,95 \% \mathrm{CI}=0.23$ 0.58) were significantly less likely to be postmenopausal. Having multiple children and having children at younger ages were protective for luminal A $(\mathrm{AOR}=0.62,95 \% \mathrm{CI}=0.39$ 1.08 , comparing $\geq 3$ children to nulliparity; $\mathrm{AOR}=0.61,95 \%$ $\mathrm{CI}=0.38-0.99$, comparing $<26$ years to nulliparity) and luminal $\mathrm{B}$ patients $(\mathrm{AOR}=0.56,95 \% \mathrm{CI}=0.35-0.90$, comparing $\geq 3$ children to nulliparity; $\mathrm{AOR}=0.59,95 \% \mathrm{CI}=0.39$ 0.88 , comparing $<26$ years to nulliparity), but not for HER2 overexpressing (AOR $=1.01,95 \% \mathrm{CI}=0.43-2.40$, comparing $\geq 3$ children to nulliparity; $\mathrm{AOR}=1.02,95 \% \mathrm{CI}=0.47-$ 2.22 , comparing $<26$ years to nulliparity) or triple negative patients $(\mathrm{AOR}=1.38,95 \% \mathrm{CI}=0.65-2.93$, comparing $\geq 3$ children to nulliparity; $\mathrm{AOR}=1.60,95 \% \mathrm{CI}=0.83-3.08$, comparing $<26$ years to nulliparity). Overweight/obesity was associated with increased risk for all subtypes except for 
Table 1 Distribution of selected breast cancer risk factors among 955 breast cancer cases in Hong Kong ${ }^{\mathrm{a}}$

\begin{tabular}{|c|c|c|c|c|c|}
\hline Characteristics & $\begin{array}{l}\text { Luminal A } \\
(n=294)\end{array}$ & $\begin{array}{l}\text { Luminal B } \\
(n=393)\end{array}$ & $\begin{array}{l}\text { HER2 overexpressing } \\
(n=99)\end{array}$ & $\begin{array}{l}\text { Triple negative } \\
(n=137)\end{array}$ & $P_{\text {heterogeneity }}{ }^{\mathrm{b}}$ \\
\hline Age, mean $\pm \mathrm{SD}$ & $58.48 \pm 12.0$ & $56.46 \pm 11.5$ & $55.07 \pm 9.3$ & $54.72 \pm 12.1$ & 0.04 \\
\hline $\begin{array}{l}\text { Familial breast cancer history, } n \\
\qquad(\%)\end{array}$ & & & & & 0.37 \\
\hline Never & $263(89.5)$ & $342(87.0)$ & $91(91.9)$ & $125(91.2)$ & \\
\hline Ever & $31(10.5)$ & $51(13.0)$ & $8(8.1)$ & $12(8.8)$ & \\
\hline $\begin{array}{l}\text { Age at menarche (years), } \\
\text { mean } \pm \text { SD }\end{array}$ & $13.72 \pm 2.0$ & $13.59 \pm 2.0$ & $13.98 \pm 2.0$ & $13.50 \pm 2.0$ & 0.23 \\
\hline \multicolumn{6}{|l|}{ Age at first birth (years) } \\
\hline Never & $46(16.7)$ & $72(19.3)$ & $12(13.2)$ & $15(12.0)$ & 0.34 \\
\hline$<26$ & $103(37.5)$ & $150(40.1)$ & $35(38.5)$ & $57(45.6)$ & \\
\hline$\geq 26$ & $126(42.9)$ & $152(40.6)$ & $44(48.4)$ & $53(42.4)$ & \\
\hline Menopausal status, $n(\%)$ & & & & & 0.61 \\
\hline Pre-menopausal & $96(35.2)$ & $126(33.6)$ & $27(30.0)$ & $49(38.3)$ & \\
\hline Post-menopausal & $177(64.8)$ & $249(63.4)$ & $63(70.0)$ & $79(61.7)$ & \\
\hline \multicolumn{6}{|l|}{ Breastfeeding frequency, $n(\%)$} \\
\hline Never & $165(59.6)$ & $232(61.7)$ & $62(67.4)$ & $88(64.2)$ & 0.40 \\
\hline Less than 1 year & $46(16.6)$ & $68(17.3)$ & $15(16.3)$ & $21(15.3)$ & \\
\hline More than 1 year & $66(23.8)$ & $76(19.3)$ & $15(16.3)$ & $19(13.9)$ & \\
\hline Parity, $n(\%)$ & & & & & 0.30 \\
\hline Nulliparous & $46(16.7)$ & $72(19.3)$ & $12(13.0)$ & $15(11.8)$ & \\
\hline $1-2$ & $151(54.7)$ & $193(51.6)$ & $55(59.8)$ & $80(63.0)$ & \\
\hline$\geq 3$ & $79(28.6)$ & $109(29.1)$ & $25(27.2)$ & $32(25.2)$ & \\
\hline Body mass index $\left(\mathrm{kg} / \mathrm{m}^{2}\right), n(\%)$ & & & & & 0.87 \\
\hline Normal and underweight $(<25.0)$ & $169(60.6)$ & $240(65.6)$ & $60(66.7)$ & $81(62.3)$ & \\
\hline Overweight (25.0-29.9) & $84(30.1)$ & $98(26.8)$ & $24(26.7)$ & $39(30.0)$ & \\
\hline Obese $(\geq 30.0)$ & $26(9.3)$ & $28(7.7)$ & $6(6.7)$ & $10(7.7)$ & \\
\hline
\end{tabular}

${ }^{a}$ Participants with missing values were excluded from the analysis

${ }^{\mathrm{b}} p$ value was used to compare the difference of each selected factor across breast cancer subtypes

HER2 overexpressing women $(\mathrm{AOR}=1.38,95 \% \mathrm{CI}=0.83$ 2.28). The association for breastfeeding was not significant for any subtype. Similar results were obtained in the sensitivity analysis removing 59 control patients with ovarian and related diseases from our model (Supplementary Table 2).

We further conducted a stratified analysis by menopausal status for parity and BMI (Table 4). Parity was associated with a reduced risk in postmenopausal luminal patients $(\mathrm{AOR}=$ $0.36,95 \% \mathrm{CI}=0.22-0.60$, comparing $\geq 3$ children to nulliparity) but an increased risk for premenopausal nonluminal women $(\mathrm{AOR}=4.10,95 \% \mathrm{CI}=1.49-11.28$, comparing $\geq 3$ children to nulliparity). Overweight or obesity was associated with increased risk for all subtypes except for premenopausal luminal patients.

\section{Discussion}

This study is the first to demonstrate that there were notable variations in the effects of several reproductive-related factors (age of first birth, breastfeeding, parity) on specific breast cancer subtypes among Chinese women in Hong Kong. Consistent with findings from previous studies based primarily on Western populations, we found that parity and younger age at first childbirth were protective for luminal breast cancer only [21]. In contrast to what was seen in Western women, overweight or obesity was not associated with reduced breast cancer risk among premenopausal women, regardless of the subtype. Given the increased risk associated with obesity for all breast cancer subtypes among both pre- or postmenopausal women except for premenopausal luminal patients, our results highlight the importance of weight control in breast cancer prevention in Asian women.

Early age at first birth and parity are established reproductive-related protective factors for breast cancer. Consistent with previous studies [10,22, 23], we found that the similar differential effect of parity and age at first birth by subtypes and menopausal status. Also in line with findings from previous studies especially conducted in African American women [24], we found that long-term breastfeeding 
Table 2 Case-case odds ratios (ORs) and 95\% confidence intervals (95\% CIs) for associations between selected breast cancer risk factors and subtypes among Chines breast cancer patients in Hong Kong ${ }^{a}$

\begin{tabular}{|c|c|c|c|c|c|c|}
\hline \multirow[t]{2}{*}{ Characteristics } & \multicolumn{2}{|l|}{ Luminal B $(n=393)$} & \multicolumn{2}{|c|}{ HER2 overexpressing $(n=99)$} & \multicolumn{2}{|c|}{ Triple negative $(n=137)$} \\
\hline & $\operatorname{AOR}(95 \% \mathrm{CI})^{\mathrm{bc}}$ & $p$ value & $\operatorname{AOR}(95 \% \mathrm{CI})^{\mathrm{b}, \mathrm{c}}$ & $p$ value & $\operatorname{AOR}(95 \% \mathrm{CI})^{\mathrm{b}, \mathrm{c}}$ & $p$ value \\
\hline Age at menarche (years) & $0.99(0.90-1.08)$ & 0.81 & $1.09(0.90-1.26)$ & 0.21 & $0.96(0.84-1.09)$ & 0.50 \\
\hline \multicolumn{7}{|l|}{ Age at first birth (years) } \\
\hline Never & 1.00 & & 1.00 & & 1.00 & \\
\hline$<26$ & $0.99(0.59-1.67)$ & 0.96 & $2.05(0.86-4.87)$ & 0.10 & $2.61(1.22-5.58)$ & 0.01 \\
\hline$\geq 26$ & $0.72(0.44-1.18)$ & 0.19 & $1.89(0.82-4.31)$ & 0.13 & $1.63(0.78-3.38)$ & 0.19 \\
\hline \multicolumn{7}{|l|}{ Menopausal status } \\
\hline Pre-menopausal & 1.00 & & 1.00 & & 1.00 & \\
\hline Post-menopausal & $1.76(1.07-2.88)$ & 0.03 & $3.40(1.56-7.39)$ & 0.02 & $2.39(1.18-4.82)$ & 0.02 \\
\hline \multicolumn{7}{|l|}{ Breastfeeding frequency } \\
\hline Never & 1.00 & & 1.00 & & 1.00 & \\
\hline Less than 1 year & $1.24(0.77-2.00)$ & 0.38 & $0.61(0.27-1.35)$ & 0.22 & $0.74(0.39-1.41)$ & 0.36 \\
\hline More than 1 year & $1.04(0.65-1.66)$ & 0.89 & $0.56(0.26-1.19)$ & 0.13 & $0.65(0.34-1.24)$ & 0.19 \\
\hline \multicolumn{7}{|l|}{ Parity } \\
\hline Nulliparous & 1.00 & & 1.00 & & 1.00 & \\
\hline $1-2$ & $0.80(0.49-1.29)$ & 0.36 & $1.98(0.88-4.42)$ & 0.10 & $1.97(0.97-3.99)$ & 0.06 \\
\hline$\geq 3$ & $0.93(0.52-1.65)$ & 0.79 & $2.10(0.79-5.53)$ & 0.14 & $2.17(0.92-5.11)$ & 0.08 \\
\hline \multicolumn{7}{|l|}{ Body mass index $\left(\mathrm{kg} / \mathrm{m}^{2}\right)$} \\
\hline Normal and underweight $(<25.0)$ & 1.00 & & 1.00 & & 1.00 & \\
\hline Overweight and obese $(\geq 25.0-29.9)$ & $0.95(0.79-1.13)$ & 0.56 & $0.91(0.68-1.21)$ & 0.51 & $1.06(0.83-1.35)$ & 0.65 \\
\hline
\end{tabular}

was less prevalent in HER 2 overexpressing and triple negative patients compared with luminal A patients and breastfeeding had a stronger protection for these two subtypes, although the differences did not reach the statistical significance probably due to small sample size.

Consistent with prior study from Southwest China, higher BMI was associated with increased breast cancer risk regardless of subtypes, which appears to be unique in Asian populations [12]. Although the association between high BMI and breast cancer risk is stronger for postmenopausal women, the similar strength of association was found for premenopausal women with non-luminal subtypes. However, a previous study using data from a series of breast cancer case-control studies conducted in the USA also found that breast cancer risk factor associations may vary by method of detection [25]. For example, they showed that the association between obesity and increased breast cancer risk among postmenopausal women was stronger for mammography-detected than for woman/clinician-detected breast cancer. Among premenopausal women, there was a positive association between obesity and risk of mammography-detected cancer but an inverse association between obesity and risk of woman/cliniciandetected cancer [25]. There is no population-based screening program in Hong Kong and cancer in the majority of breast cancer cases in our study was woman/clinician-detected. Thus, the variation of detection methods is unlikely to have the significant influence on the heterogeneous associations by subtype we observed.

In this study, we found that luminal patients were more likely to be premenopausal compared with controls or other breast cancer subtypes. Several previous studies conducted in China found similar patterns $[22,26]$. This association is likely driven by the birth cohort effect, represented by increasing exposures to Westernized lifestyle-associated risk factors among younger women and these risk factors are known to have stronger associations with luminal breast cancers. In contrast, older women who had experienced menopause were more likely to have the traditional lifestyles and therefore had lower risk for developing luminal breast cancer. Alternatively, Asian women may have distinct hormoneassociated etiology, as recently suggested by Lin et al. in a study comparing age-specific probabilities of breast tumor 
Table 3 Case-control odds ratios (ORs) and 95\% confidence intervals (95\% CIs) for overall and breast cancer subtypes specific risks among Hong Kong Chinese women ${ }^{\mathrm{a}}$

\begin{tabular}{|c|c|c|c|c|c|c|}
\hline \multirow[t]{2}{*}{ Characteristics } & \multirow{2}{*}{$\begin{array}{l}\text { Control } \\
\text { (Reference) } \\
(n=1013) \\
n(\%)\end{array}$} & \multirow[b]{2}{*}{$\begin{array}{l}\text { All cases } \\
(n=1156) \\
\text { AOR }(95 \% \mathrm{CI})^{\mathrm{b}}\end{array}$} & \multicolumn{4}{|l|}{ Breast cancer cases } \\
\hline & & & $\begin{array}{l}\text { Luminal A } \\
(n=294) \\
\text { AOR }(95 \% \mathrm{CI})^{\mathrm{b}}\end{array}$ & $\begin{array}{l}\text { Luminal B } \\
(n=393) \\
\text { AOR }(95 \% \mathrm{CI})^{\mathrm{b}}\end{array}$ & $\begin{array}{l}\text { HER2 overexpressing } \\
(n=99) \\
\text { AOR }(95 \% \mathrm{CI})^{\mathrm{b}}\end{array}$ & $\begin{array}{l}\text { Triple negative } \\
(n=137) \\
\text { AOR }(95 \% \mathrm{CI})^{\mathrm{b}}\end{array}$ \\
\hline Age at menarche (years) & $13.76 \pm 2.3$ & $0.97(0.93-1.02)$ & $0.98(0.91-1.06)$ & $0.98(0.91-1.05)$ & $1.05(0.94-1.18)$ & $0.96(0.87-1.06)$ \\
\hline \multicolumn{7}{|l|}{ Age at first birth (years) } \\
\hline Never & $170(17.4)$ & 1.00 & 1.00 & 1.00 & 1.00 & 1.00 \\
\hline$<26$ & $435(44.4)$ & $0.71(0.52-0.96)$ & $0.61(0.38-0.99)$ & $0.59(0.39-0.88)$ & $1.02(0.47-2.22)$ & $1.60(0.83-3.08)$ \\
\hline$\geq 26$ & $374(38.2)$ & $0.89(0.66-1.19)$ & $0.90(0.57-1.42)$ & $0.64(0.43-0.95)$ & $1.34(0.64-2.80)$ & $1.46(0.76-2.78)$ \\
\hline \multicolumn{7}{|l|}{ Menopausal status } \\
\hline Pre-menopausal & $341(35.6)$ & 1.00 & 1.00 & 1.00 & 1.00 & 1.00 \\
\hline Post-menopausal & $616(64.4)$ & $0.58(0.44-0.77)$ & $0.38(0.24-0.60)$ & $0.73(0.50-1.08)$ & $1.27(0.64-2.56)$ & $0.84(0.47-1.51)$ \\
\hline \multicolumn{7}{|l|}{ Breastfeeding frequency } \\
\hline Never & $629(64.0)$ & 1.00 & 1.00 & 1.00 & 1.00 & 1.00 \\
\hline Less than 1 year & $142(14.4)$ & $1.23(0.92-1.62)$ & $1.26(0.82-1.94)$ & $1.56(1.07-2.26)$ & $0.80(0.40-1.60)$ & $1.00(0.58-1.73)$ \\
\hline More than 1 year & $212(21.6)$ & $0.94(0.71-1.23)$ & $1.06(0.70-1.60)$ & $1.10(0.76-1.60)$ & $0.58(0.29-1.18)$ & $0.63(0.35-1.14)$ \\
\hline \multicolumn{7}{|l|}{ Parity } \\
\hline Nulliparous & $169(17.1)$ & 1.00 & 1.00 & 1.00 & 1.00 & 1.00 \\
\hline $1-2$ & $528(53.5)$ & $0.84(0.64-1.12)$ & $0.80(0.52-1.25)$ & $0.63(0.43-0.92)$ & $1.26(0.62-2.58)$ & $1.58(0.85-2.93)$ \\
\hline$\geq 3$ & $290(29.4)$ & $0.67(0.48-0.95)$ & $0.62(0.39-1.08)$ & $0.56(0.35-0.90)$ & $1.01(0.43-2.40)$ & $1.38(0.65-2.93)$ \\
\hline \multicolumn{7}{|l|}{ Body mass index $\left(\mathrm{kg} / \mathrm{m}^{2}\right)$} \\
\hline Normal and underweight $(<25.0)$ & $625(73.4)$ & 1.00 & 1.00 & 1.00 & 1.00 & 1.00 \\
\hline Overweight and obese $(\geq 25.0-29.9)$ & $177(20.8)$ & $1.50(1.22-1.86)$ & $1.24(1.06-1.46)$ & $1.21(1.05-1.39)$ & $1.38(0.83-2.28)$ & $1.33(1.09-1.64)$ \\
\hline
\end{tabular}

${ }^{\text {a }}$ Participants with missing values were excluded from the analysis

${ }^{b}$ The models were adjusted for age, family history of breast cancer, age at menarche, age at first birth/parity, menopausal status, breastfeeding frequency, and body mass index

subtypes between Asian and USA women using data from eight hospital-based cancer registries in East Asian countries and the Surveillance, Epidemiology, and End Results (SEER) Program [27].

Our study demonstrated varied associations between obesity, specific reproductive-related factors, and breast cancer subtypes using case-case and case-control analyses, which had been less investigated in Asian populations. Results of our study thus contributed new evidence to the current body of literature regarding etiologic heterogeneity by breast cancer subtypes in Asian populations. All participants in this study were recruited from three large public hospitals, with a high response rate $(88.4 \%)$. Test-retest reliability was conducted among 158 cases and 153 controls at least 1 month after the initial interview, showing an overall Kappa consistency rate of $83 \%$ for the items included in the test-retest reliability study. However, several limitations should be noted. Inconsistent with previous study [26], the proportion of luminal B was higher than luminal $\mathrm{A}$ in this study. If we used the same classification, the proportion of luminal $\mathrm{A}(\mathrm{ER}+$ and/or PR+, HER2-) will be higher than luminal $\mathrm{B}$ (ER+ and/or PR+, HER2+). In our study, we classified our cases into different intrinsic subtypes according to the suggestion by the 2013 St Gallen International Expert Consensus Definition in order to make the classification more precise, in which another study using St Gallen classification have a similar proportion of luminal $\mathrm{A}$ and luminal B [11]. We classified HER2 IHC 2+ patients with missing FISH/CISH data as HER2 negative, which might have led to a misclassification in HER2 status. However, we confirmed that around $83 \%$ of HER2 IHC $2+$ cases were HER2 - in the database of one of our collaboration hospitals, suggesting that our major findings are unlikely to be driven by the misclassification. Similar to any other casecontrol studies, potential recall bias may not be totally avoided in our study, but we tried to minimize it by only recruiting recently diagnosed incident breast cancer patients who were introduced this study as a "general women health study." We are aware that the missing data of BMI may be a concern, and thus we demonstrated the distribution of selected characteristics by the availability of BMI (Supplementary Table 1). We found that women with 
Table 4 Case-control odds ratios (ORs) and 95\% confidence intervals (95\% CIs) for breast cancer subtypes specific risks associated with body mass index and parity among Hong Kong Chinese women, stratified by menopausal status ${ }^{\mathrm{a}}$

\begin{tabular}{|c|c|c|c|c|}
\hline & \multicolumn{2}{|l|}{ Premenopausal } & \multicolumn{2}{|l|}{ Postmenopausal } \\
\hline & $\begin{array}{l}\text { Lumina A and } \\
\text { luminal B } \\
\text { AOR }(95 \% \mathrm{CI})^{\mathrm{b}}\end{array}$ & $\begin{array}{l}\text { HER } 2 \text { overexpressing and triple } \\
\text { negative } \\
\text { AOR }(95 \% \mathrm{CI})^{\mathrm{b}}\end{array}$ & $\begin{array}{l}\text { Lumina A and } \\
\text { luminal B } \\
\text { AOR }(95 \% \mathrm{CI})^{\mathrm{b}}\end{array}$ & $\begin{array}{l}\text { HER } 2 \text { overexpressing and triple } \\
\text { negative } \\
\text { AOR }(95 \% \mathrm{CI})^{\mathrm{b}}\end{array}$ \\
\hline \multicolumn{5}{|l|}{ Parity } \\
\hline Nulliparous & 1.00 & 1.00 & 1.00 & 1.00 \\
\hline $1-2$ & $1.03(0.63-1.67)$ & $1.95(0.88-4.36)$ & $0.45(0.28-0.71)$ & $0.85(0.50-1.80)$ \\
\hline$\geq 3$ & $1.22(0.57-2.57)$ & $4.10(1.49-11.28)$ & $0.36(0.22-0.60)$ & $0.65(0.32-1.35)$ \\
\hline \multicolumn{5}{|l|}{ Body mass index $\left(\mathrm{kg} / \mathrm{m}^{2}\right)$} \\
\hline $\begin{array}{l}\text { Normal and underweight } \\
(<25.0)\end{array}$ & 1.00 & 1.00 & 1.00 & 1.00 \\
\hline $\begin{array}{l}\text { Overweight and obese } \\
(\geq 25.0-29.9)\end{array}$ & $1.06(0.86-1.31)$ & $1.31(0.98-1.75)$ & $1.33(1.14-1.54)$ & $1.26(1.02-1.56)$ \\
\hline
\end{tabular}

missing BMI tend to be older and have a higher missing rate in reproductive-related factors. Furthermore, the selection of hospital-based controls may not represent the general population. We only used age and recruitment hospitals as matching variables when recruiting control patients (for example, we did not collect their lipid profiles or insulin sensitivity for matching), which may have led to biased estimates. To address this question, we recruited controls from the same hospitals with a variety of disease spectrum that were not related to any type of breast diseases and exposures of interest. Previous hospital-based case-control studies provided evidence for a similar magnitude of risk estimates obtained from hospital-based and population-based controls especially for controls with a variety of disease types [28]. We also conducted sensitivity analysis by excluding controls patients of ovarian and related diseases, metabolic diseases, and circadian system diseases that were related to the exposure of interest, and the associations between reproductive-related factors and BMI and overall breast cancer remained unchanged after the restriction (Supplementary Table 2); we also performed sensitivity analysis by only excluding controls patients of ovarian and related diseases and circadian system diseases (i.e., including control patients with endocrine, nutritional, and metabolic diseases) and results remained consistent (Supplementary Table 2). In addition, relative risks for those established risk factors in our study were similar to what were previously reported in most other studies, suggesting that the bias of control selection may not pose a major impact on our results. Finally, we did not correct for multiple comparisons when testing multiple risk factors and subtypes of breast cancer. Nevertheless, the majority of statistical tests were based on prior hypotheses supported by previous studies.

\section{Conclusions}

In conclusion, this study demonstrated heterogeneous associations of established breast cancer risk factors with different subtypes of breast cancer in an Asian population. These results, which warrant future investigations in large populationbased studies in additional Asian populations, may have important implications on breast cancer subtype-specific risk prediction and prevention.

Code Availability Not applicable.

Authors' Contributions LAT designed and oversaw the conduct of this present study. XRY contributed ideas in study design, as well as commented and revised the current manuscript. PMYL reviewed the literature, analyzed the data, and drafted the manuscript under the supervision of LAT and XRY. CHK coordinated the data collection and gave suggestion on the current manuscript. WF contributed to the questionnaire design and liaison with the studied hospitals. CHK, WCY, and YCY organized and managed the field work at Princess Margaret Hospital. WCC and CW organized and managed the field work at North District Hospital. SHL and KHT organized and managed the field work at Yan Chai Hospital. All authors contributed to the development of this manuscript and approved the final version of this manuscript.

Funding Information The work was supported by the Research Grants Council of Hong Kong (Grant number 474811).

Data Availability The results and materials described in the article, and the relevant data related to reproductive factors that used in this article, are available from the corresponding author on reasonable request. 


\section{Compliance with Ethical Standards}

Conflict of Interest The authors declare that they have no conflict of interest.

Ethics Approval This study was approved by the Joint Chinese University of Hong Kong-New Territories East Cluster Clinical Research Ethics Committee and the Ethics Committee of Kowloon West Cluster.

Consent to Participate All participants signed written informed consent forms before the fieldwork prior to the interviews.

\section{Consent for Publication Not applicable.}

Abbreviations AOR, adjusted odds ratio; 95\% CI, 95\% confidence interval; ER, estrogen receptor; PR, progesterone receptor; HER2, human epidermal growth factor; BMI, body mass index; IHC, immunohistochemistry; FISH, fluorescence in situ hybridization; CISH, chromogenic in situ hybridization

\section{References}

1. Sorlie T, Tibshirani R, Parker J, Hastie T, Marron JS, Nobel A, Deng S, Johnsen H, Pesich R, Geisler S et al (2003) Repeated observation of breast tumor subtypes in independent gene expression data sets. Proc Natl Acad Sci U S A 100(14):8418-8423

2. Goldhirsch A, Winer EP, Coates AS, Gelber RD, Piccart-Gebhart M, Thurlimann B, Senn HJ, Panel M (2013) Personalizing the treatment of women with early breast cancer: highlights of the St Gallen International Expert Consensus on the Primary Therapy of Early Breast Cancer 2013. Ann Oncol 24(9):2206-2223

3. Prat A, Pineda E, Adamo B, Galvan P, Fernandez A, Gaba L, Diez M, Viladot M, Arance A, Munoz M (2015) Clinical implications of the intrinsic molecular subtypes of breast cancer. Breast 24(Suppl 2):S26-S35

4. Song N, Choi JY, Sung H, Chung S, Song M, Park SK, Han W, Lee JW, Kim MK, Yoo KY, Ahn SH, Noh DY, Kang D (2014) Heterogeneity of epidemiological factors by breast tumor subtypes in Korean women: a case-case study. Int J Cancer 135(3):669-681

5. Anstey EH, Shoemaker ML, Barrera CM, O'Neil ME, Verma AB, Holman DM (2017) Breastfeeding and breast cancer risk reduction: implications for black mothers. Am J Prev Med 53(3S1):S40-S46

6. Abubakar M, Chang-Claude J, Ali HR, Chatterjee N, Coulson P, Daley F, Blows F, Benitez J, Milne RL, Brenner H, Stegmaier C, Mannermaa A, Rudolph A, Sinn P, Couch FJ, Devilee P, Tollenaar RAEM, Seynaeve C, Figueroa J, Lissowska J, Hewitt S, Hooning MJ, Hollestelle A, Foekens R, Koppert LB, Investigators CF, Bolla MK, Wang Q, Jones ME, Schoemaker MJ, Keeman R, Easton DF, Swerdlow AJ, Sherman ME, Schmidt MK, Pharoah PD, GarciaClosas M (2018) Etiology of hormone receptor positive breast cancer differs by levels of histologic grade and proliferation. Int $\mathrm{J}$ Cancer 143(4):746-757

7. Islami F, Liu Y, Jemal A, Zhou J, Weiderpass E, Colditz G, Boffetta P, Weiss M (2015) Breastfeeding and breast cancer risk by receptor status-a systematic review and meta-analysis. Ann Oncol 26(12): 2398-2407

8. Lambertini M, Santoro L, Del Mastro L, Nguyen B, Livraghi L, Ugolini D, Peccatori FA, Azim HA Jr (2016) Reproductive behaviors and risk of developing breast cancer according to tumor subtype: a systematic review and meta-analysis of epidemiological studies. Cancer Treat Rev 49:65-76
9. Martinez ME, Wertheim BC, Natarajan L, Schwab R, Bondy M, Daneri-Navarro A, Meza-Montenegro MM, Gutierrez-Millan LE, Brewster A, Komenaka IK, Thompson PA (2013) Reproductive factors, heterogeneity, and breast tumor subtypes in women of mexican descent. Cancer Epidemiol Biomark Prev 22(10):1853-1861

10. Yang XR, Chang-Claude J, Goode EL, Couch FJ, Nevanlinna H, Milne RL, Gaudet M, Schmidt MK, Broeks A, Cox A, Fasching PA, Hein R, Spurdle AB, Blows F, Driver K, Flesch-Janys D, Heinz J, Sinn P, Vrieling A, Heikkinen T, Aittomäki K, Heikkilä P, Blomqvist C, Lissowska J, Peplonska B, Chanock S, Figueroa J, Brinton L, Hall P, Czene K, Humphreys K, Darabi H, Liu J, van 't Veer LJ, van Leeuwen FE, Andrulis IL, Glendon G, Knight JA, Mulligan AM, O’Malley FP, Weerasooriya N, John EM, Beckmann MW, Hartmann A, Weihbrecht SB, Wachter DL, Jud SM, Loehberg CR, Baglietto L, English DR, Giles GG, McLean CA, Severi G, Lambrechts D, Vandorpe T, Weltens C, Paridaens R, Smeets A, Neven P, Wildiers H, Wang X, Olson JE, Cafourek V, Fredericksen Z, Kosel M, Vachon C, Cramp HE, Connley D, Cross SS, Balasubramanian SP, Reed MWR, Dörk T, Bremer M, Meyer A, Karstens JH, Ay A, Park-Simon TW, Hillemanns P, Arias Pérez JI, Rodríguez PM, Zamora P, Benítez J, Ko YD, Fischer HP, Hamann U, Pesch B, Brüning T, Justenhoven C, Brauch H, Eccles DM, Tapper WJ, Gerty SM, Sawyer EJ, Tomlinson IP, Jones A, Kerin M, Miller N, McInerney N, Anton-Culver H, Ziogas A, Shen CY, Hsiung CN, Wu PE, Yang SL, Yu JC, Chen ST, Hsu GC, Haiman CA, Henderson BE, le Marchand L, Kolonel LN, Lindblom A, Margolin S, Jakubowska A, Lubiński J, Huzarski T, Byrski T, Górski B, Gronwald J, Hooning MJ, Hollestelle A, van den Ouweland AMW, Jager A, Kriege M, Tilanus-Linthorst MMA, Collée M, Wang-Gohrke S, Pylkäs K, Jukkola-Vuorinen A, Mononen K, Grip M, Hirvikoski P, Winqvist R, Mannermaa A, Kosma VM, Kauppinen J, Kataja V, Auvinen P, Soini Y, Sironen R, Bojesen SE, Dynnes Ørsted D, Kaur-Knudsen D, Flyger H, Nordestgaard BG, Holland H, Chenevix-Trench G, Manoukian S, Barile M, Radice P, Hankinson SE, Hunter DJ, Tamimi R, Sangrajrang S, Brennan P, McKay J, Odefrey F, Gaborieau V, Devilee P, Huijts PEA, Tollenaar RAEM, Seynaeve C, Dite GS, Apicella C, Hopper JL, Hammet F, Tsimiklis H, Smith LD, Southey MC, Humphreys MK, Easton D, Pharoah P, Sherman ME, Garcia-Closas M (2011) Associations of breast cancer risk factors with tumor subtypes: a pooled analysis from the Breast Cancer Association Consortium studies. J Natl Cancer Inst 103(3):250-263

11. Abubakar M, Sung H, Bcr D, Guida J, Tang TS, Pfeiffer RM, Yang XR (2018) Breast cancer risk factors, survival and recurrence, and tumor molecular subtype: analysis of 3012 women from an indigenous Asian population. Breast Cancer Res 20(1):114

12. Li H, Sun X, Miller E, Wang Q, Tao P, Liu L, Zhao Y, Wang M, Qi Y, Li J (2017) BMI, reproductive factors, and breast cancer molecular subtypes: a case-control study and meta-analysis. J Epidemiol 27(4):143-151

13. CHP (2019) Breast Cancer. Department of Health, Hong Kong https://www.chp.gov.hk/en/healthtopics/content/25/53.html. Accessed 15 Dec 2019

14. Yap YS, Lu YS, Tamura K, Lee JE, Ko EY, Park YH, Cao AY, Lin $\mathrm{CH}$, Toi M, Wu J et al (2019) Insights into breast cancer in the east vs the west: a review. JAMA Oncol

15. Song Y, Ma J, Agardh A, Lau PW, Hu P, Zhang B (2015) Secular trends in age at menarche among Chinese girls from 24 ethnic minorities, 1985 to 2010. Glob Health Action 8:26929

16. CHP (2018) Marriage, fertility and family conditions. Census and Statistic Department, Hong Kong https://www.censtatd.gov.hk/ $\mathrm{hkstat} / \mathrm{sub} / \mathrm{gender} / \mathrm{marr}$ fert_and_family_con/index.jsp. Accessed 15 Dec 2019 
17. CHP (2017) Statistics on behavioural risk factors. Department of Health, Hong Kong https://www.chp.gov.hk/en/static/24016.html. Accessed 15 Dec 2019

18. Amadou A, Ferrari P, Muwonge R, Moskal A, Biessy C, Romieu I, Hainaut P (2013) Overweight, obesity and risk of premenopausal breast cancer according to ethnicity: a systematic review and doseresponse meta-analysis. Obes Rev 14(8):665-678

19. Qureshi A, Pervez S (2010) Allred scoring for ER reporting and it's impact in clearly distinguishing ER negative from ER positive breast cancers. J Pak Med Assoc 60(5):350-353

20. Britt K, Ashworth A, Smalley M (2007) Pregnancy and the risk of breast cancer. Endocr Relat Cancer 14:907-933

21. Ursin G, Bernstein L, Lord SJ, Karim R, Deapen D, Press MF, Daling JR, Norman SA, Liff JM, Marchbanks PA, Folger SG, Simon MS, Strom BL, Burkman RT, Weiss LK, Spirtas R (2005) Reproductive factors and subtypes of breast cancer defined by hormone receptor and histology. Br J Cancer 93(3):364-371

22. Bao PP, Shu XO, Gao YT, Zheng Y, Cai H, Deming SL, Ruan ZX, $\mathrm{Su}$ Y, Gu K, Lu W, Zheng W (2011) Association of hormonerelated characteristics and breast cancer risk by estrogen receptor/ progesterone receptor status in the shanghai breast cancer study. Am J Epidemiol 174(6):661-671

23. Shantakumar S, Terry MB, Teitelbaum SL, Britton JA, Millikan RC, Moorman PG, Neugut AI, Gammon MD (2007) Reproductive factors and breast cancer risk among older women. Breast Cancer Res Treat 102(3):365-374
24. Palmer JR, Viscidi E, Troester MA, Hong CC, Schedin P, Bethea TN, Bandera EV, Borges V, McKinnon C, Haiman CA, Lunetta K, Kolonel LN, Rosenberg L, Olshan AF, Ambrosone CB (2014) Parity, lactation, and breast cancer subtypes in African American women: results from the AMBER Consortium. J Natl Cancer Inst 106(10)

25. Sprague BL, Gangnon RE, Hampton JM, Egan KM, Titus LJ, Kerlikowske K, Remington PL, Newcomb PA, Trentham-Dietz A (2015) Variation in breast cancer-risk factor associations by method of detection: results from a series of case-control studies. Am J Epidemiol 181(12):956-969

26. Xing P, Li J, Jin F (2010) A case-control study of reproductive factors associated with subtypes of breast cancer in Northeast China. Med Oncol 27(3):926-931

27. Lin CH, Yap YS, Lee KH, Im SA, Naito Y, Yeo W, Ueno T, Kwong A, Li H, Huang SM, Leung R, Han W, Tan B, Hu FC, Huang CS, Cheng AL, Lu YS, The Asian Breast Cancer Cooperative Group (2019) Contrasting epidemiology and clinicopathology of female breast cancer in Asians versus the US population. J Natl Cancer Inst 111:1298-1306

28. Li L, Zhang M, Holman D (2011) Population versus hospital controls for case-control studies on cancers in Chinese hospitals. BMC Med Res Methodol 11:167

Publisher's Note Springer Nature remains neutral with regard to jurisdictional claims in published maps and institutional affiliations. 